\title{
Are There Any Connections between Language Deficits and Cognitive Slowing in Alzheimer's Disease?
}

\author{
Michael Schecker ${ }^{c}$ Carsten Kochler ${ }^{c}$ Klaus Schmidtke ${ }^{b}$ Reinhold Rauh ${ }^{a}$ \\ ${ }^{a}$ Klinik für Psychiatrie, Psychotherapie und Psychosomatik im Kindes- und Jugendalter, \\ Universität Freiburg, Freiburg, ${ }^{\mathrm{b}}$ Klinik für Hirnleistungsstörungen Klausenbach, \\ Nordrach, and 'Neurolinguistisches Labor NLL, Klinik für Psychiatrie, Psychotherapie und \\ Psychosomatik im Kindes- und Jugendalter, Universität Freiburg, Freiburg, Germany
}

Key Words

Alzheimer's disease - Brain function in dementia - Cognitive slowing · Deficits in language processing

\section{Abstract}

Background: Speech disorders already occur in the early phases of Alzheimer's disease (AD). As a possible cause, problems of executive processes are discussed. Cognitive slowing is also repeatedly addressed. Aims: Are there any connections between cognitive slowing and speech disorders in AD? And is there a relationship between cognitive slowing and executive processes? Methods: The data of 72 healthy controls and 52 AD patients were examined with regard to their language performance and their response times in a computerized Stroop paradigm. Results: The AD patients showed significantly worse results in all language tests as well as much longer reaction times in all Stroop conditions, especially in the interference condition (Stroop 3). Speech errors and response times correlated with severity (MMSE), and the speech errors correlated with the reaction times in Stroop 3 (interference condition, which reflects the processing time of executive processes). Conclusion: The most interesting question now is: How are language processing and executive processing time (Stroop 3) related?

\section{Introduction}

In early stages of Alzheimer's disease (AD), there are always deficits in language processing. On the pragmatic level, these processing difficulties have been associated with executive processes and the working memory (here the central executive) [1-5] (for the use 
Schecker et al:: Are There Any Connections between Language Deficits and Cognitive Slowing in Alzheimer's Disease?

of pronouns, see [6, 7], for the resolution of ambiguity, see [8-10], and for the understanding of idioms, see [11-13]). But there is evidence that, for example, naming disorders or errors on the syntactic level also have something to do with the deterioration of working memory processes [14-17] (for an overview, see [18]).

The fact that the cognitive processing speed in AD patients is significantly reduced is also well known ('cognitive slowing', e.g. with regard to the Stroop test [19-22] or to priming experiments [23]). Is there a connection between the disorders of language processing and cognitive slowing in AD? And is it possible to identify a specific link between cognitive slowing and specifically executive processes?

\section{Methods}

\section{Subjects}

Our sample consisted of 52 subjects ( 40 female, 12 male) with mild AD (fulfilling the DSM-IV [24] and NINCDS-ADRDA criteria [25]; see also Petersen [26, 27] on the differences to mild cognitive impairment) and 72 healthy controls ( 48 female, 24 male). The average age within the experimental group was 73.8 years $(S D=5.23)$, and they had a mean of 10.8 years $(\mathrm{SD}=2.87$ ) of education. The average age within the control group was 72.6 years $(\mathrm{SD}=5.43)$, and they had a mean of 11.9 years $(\mathrm{SD}=2.2)$ of education. Both groups differed in the MMSE score [28] (AD: mean $=22.5, \mathrm{SD}=2.7$; controls: mean $=28.4, \mathrm{SD}=1.01)$. The differences were also statistically significant [ANOVA, $F(2,36)=65.8$, $p<0.001$ ]. All patients were medicated with an acetylcholinesterase inhibitor and were well adjusted.

The participants were recruited through the ZGGF (Center for Geriatrics and Gerontology), University Medical Center Freiburg, and the memory clinic of the University Hospital Heidelberg, both Germany. Additional subjects were recruited through institutions of assisted living and residential care homes for the elderly in Freiburg, as well as through advertisements in the local press.

We used the following exclusion criteria: other psychiatric or neurological disorders; a score on the 'reduced' Geriatric Depression Scale [29] of 5-15 points; receiving psychotropic drugs; $<6$ years of education; mother tongue other than German; impairments of the peripheral vision and hearing (control of the speech-relevant frequencies 500/1,000/2,000/4,000 Hz using an audiometer; excluded if hearing achievements were only about $45 \mathrm{~dB}$ ), and no righthandedness (Edinburgh Handedness Inventory [30]). All subjects were also tested for their reading comprehension (brief written requests for action).

All participants were considered to have the necessary abilities to give their informed consent for participation. Appropriate care was taken in explaining the study, and they were given sufficient time to reach a decision. It was made clear to all subjects that they would not be treated any differently if they chose not to participate.

\section{Materials and Procedure}

We used 2 types of tests. First, we tested the cognitive processing speed with the Stroop Color-Word Test [19, 21, 22, 31]. It is generally accepted that the third condition (interference condition) measures higher cognitive abilities or, more precisely, executive performance. We used a modified computerized Stroop paradigm [32]. When measuring time, we considered only correct responses.

Second, we tested the ability to represent context and to integrate contextual cues in information processing using the $\mathrm{PMA}^{\circledR}$ (Predictive Monitoring in $\mathrm{AD}$, a test package that we developed at the Neurolinguistic Laboratory Freiburg [10]). Here we used the 3 subtests shown in figures 1-3 (number of test items per test $=10$, no time limit). The statement in 


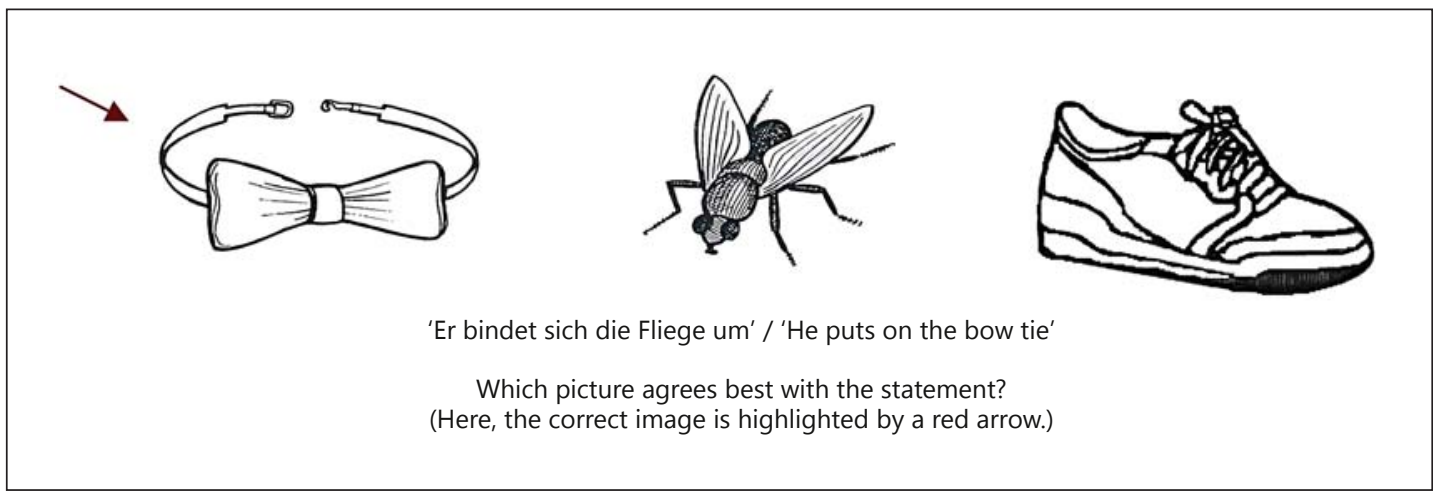

Fig. 1. Comprehension of homonyms.

Fig. 2. Comprehension of idioms.

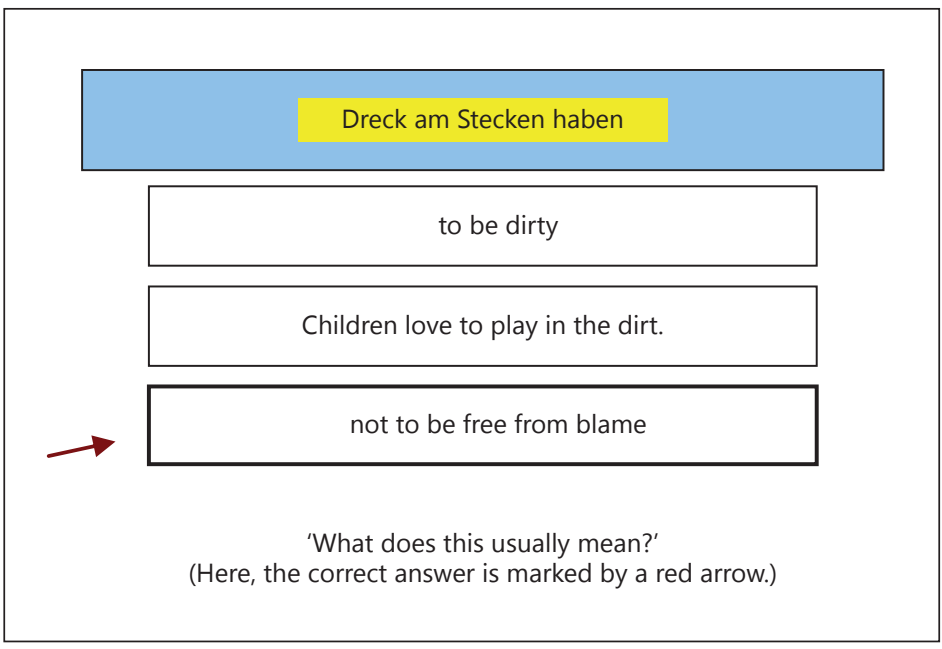

Eine Frau betritt das Café am Markt. ... trägt ein Paket unter dem Arm und schaut sich suchend um. Aber im Café sitzt niemand; nur ein Kellner arbeitet geschäftig hinter der Theke. ......... überlegt, ob sie sich setzen soll, geht aber schließlich ohne Gruß.
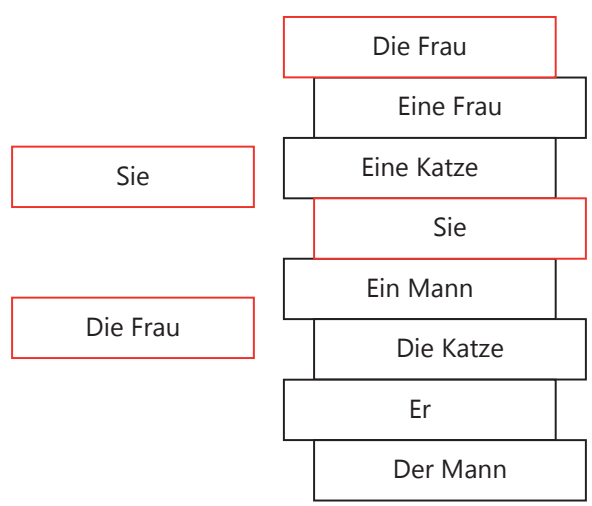

'Please insert the appropriate expressions in the gaps of the text: (Here, the correct expressions are framed in red.)

Fig. 3. Processing of pronouns. 
Table 1. Stroop performance A

\begin{tabular}{|c|c|c|c|}
\hline \multirow[t]{2}{*}{ Condition } & \multicolumn{2}{|c|}{ Response time (average), ms } & \multirow{2}{*}{$\begin{array}{l}\text { Group differences } \\
\text { (one-way ANOVA with } \\
\text { Brown-Forsythe correction) }\end{array}$} \\
\hline & controls $(n=72)$ & $\mathrm{AD}(\mathrm{n}=52)$ & \\
\hline Stroop 1 & $821(132)$ & $1,468(465)$ & $F(1,13.09)=31.00, p<0.0005$ \\
\hline Stroop 2 & $856(109)$ & $1,523(405)$ & $F(1,13.28)=28.19, p<0.0005$ \\
\hline Stroop 3 (with interference) & $941(152)$ & $2,372(726)$ & $F(1,16.24)=50.00, p<0.0005$ \\
\hline
\end{tabular}

Stroop 1: color > color (e.g. $\square>\square$ ). Stroop 2: meaning > color (e.g. 'green' > $\mathbf{\square})$. Stroop 3: color of the letters > color (e.g. 'green' $>\square$ ). In the evaluation of the processing times only the correct trials were included.

subtest 1 (fig. 1) always refers to the lower-frequency meaning of the homonym. The pictures were distributed in random order.

Could disorders of the semantic system also be relevant here? If so, then the performance in confrontational naming (see the Boston Naming Test) would also be affected. However, we did not use any black-and-white line drawings but real objects. In the processing of black-and-white line drawings, additional complex cognitive processing steps are necessary [33-35].

Each template in subtest 2 (fig. 2) was an idiom (for example 'Dreck am Stecken haben'). There were always 3 explanations offered; the correct one was to be indicated. Besides the correct explanation (the figurative meaning is 'nicht frei von Schuld sein'/'not to be free of blame'), a more or less literal explanation was given ('dreckig sein'/'be dirty'). The final explanation given wasa semantically associated statement ('Kinder spielen gern im Dreck'/'Children love to play in the dirt'). The response options were listed in random order. The subjects were requested to select appropriate expressions from a list of 8 possibilities.

In subtest 3 (fig. 3 ) the subjects were requested to select appropriate expressions from a list of always 8 possibilities.

\section{Results}

Table 1 shows the processing times (average) of the 2 simple conditions and the interference condition. The repeated-measures ANOVA shows an interaction of group and condition $[\mathrm{F}(2,28)=9.80, \mathrm{p}<0.001]$ and main effects for both, condition $[\mathrm{F}(2,28)=37.10$, $\mathrm{p}<0.0005]$ and group $[\mathrm{F}(1,29)=65.09, \mathrm{p}<0.0005]$. The multiple comparisons with Bonferroni adjustment between the different Stroop conditions in the total sample found no significant differences between the 2 simple conditions Stroop 1 and Stroop $2[F(1,29)<1$, not significant]. However, the simple conditions differ from the complex condition [Stroop 1 to Stroop 3: $F(1,29)=62.27, p<0.0005$; Stroop 2 to Stroop 3: $F(1,29)=67.76, p<0.0005]$. The same pattern is also found in the AD group [Stroop 1 to Stroop 2: $F(1,12)<1$, not significant; Stroop 1 to Stroop 3: $F(1,12)=36.55, \mathrm{p}<0.0005$; Stroop 2 to Stroop 3: $F(1,12)=$ $38.25, \mathrm{p}<0.0005]$. Table 1 shows the differences between $\mathrm{AD}$ and control subjects.

AD patients (early stages) need significantly more time than the controls, and this slowdown is already present in the simple conditions. However, it is particularly interesting that the processing times of the 2 simple conditions and the interference condition do not rise in parallel. The patients are 1.78 and 1.77 times slower than the healthy controls in Stroop 1 and Stroop 2, respectively, and 2.52 times slower in Stroop 3. Moreover, in the AD group, the 
Fig. 4. Stroop performance B. RT = Response time.

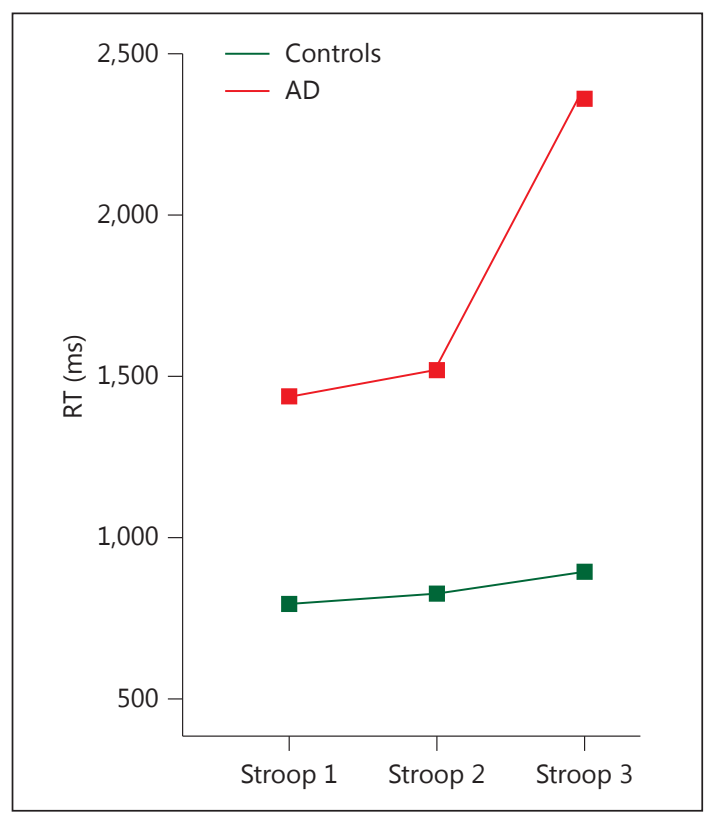

Table 2. Correlations between response time and MMSE in the

\begin{tabular}{ll}
\hline Condition & Spearman correlations (one-sided) \\
\hline Stroop 1 - MMSE & $r^{s}=-0.486, p=0.06$, n.s. \\
\hline Stroop 2 - MMSE & $r^{s}=-0.344, p=0.06$, n.s. \\
\hline Stroop 3 - MMSE & $r^{s}=-0.655, p=0.002$ \\
\hline
\end{tabular}

The correlation coefficient $r>0.5$ indicates a large effect [36]. n.s. $=$ Not significant.

increase in processing time of Stroop 2 to Stroop 3 is 10 times the corresponding increase in the controls (fig. 4).

Are there any connections between the cognitive slowing and the severity of the disease (MMSE)? Yes, but only in the AD group and only for Stroop 3 (table 2).

Table 3 shows the error rates of the PMA subtests. Because the assumption of a normal distribution for the PMA must be rejected (significant Kolmogorov-Smirnov test for all variables), we used nonparametric tests for 2 independent samples (Wilcoxon-Mann-Whitney test) to test for group differences.

In the naming task (naming of real objects), the AD patients did not differ from the controls.

A qualitative analysis of the errors in the pronoun test showed that (a) in $56.2 \%$ of the cases, a definite noun phrase was chosen (e.g. 'die Frau'/'the woman') instead of the correct definite pronoun; (b) in less than $8 \%$ of the cases, the morphological genus was wrong, obviously referenced incorrectly, and (c) in more than $89 \%$ of the cases, the errors reflected no wrong reference; the patients had very well understood to which reference the objects were addressed in the text.

Are there any connections between the PMA errors and the severity of the disease (MMSE)? Yes, but only in the AD group (table 4). In the AD group (and only there), we have also found correlations between the PMA errors and the Stroop response time in the interference condition (table 5). 
Table 3. PMA performance

\begin{tabular}{llllll}
\hline PMA subtests & PMA errors & & & \multicolumn{2}{l}{$\begin{array}{l}\text { Group differences } \\
\text { (Wilcoxon-Mann-Whitney test) }\end{array}$} \\
\cline { 2 - 3 } & controls & AD patients & & Z (two-tailed) \\
\hline Homonyms & $9.9(0.3)$ & $9.0(1.3)$ & & -2.66 & 0.009 \\
Idioms & $9.4(0.9)$ & $8.0(2.9)$ & & -2.48 & 0.014 \\
Pronouns & $5.4(0.6)$ & $3.7(1.6)$ & & -2.88 & 0.005 \\
\hline
\end{tabular}

The mean number of correct responses (SD) on the language tasks for each group and results of group differences on the language tasks (computed value of Wilcoxon-Mann-Whitney test).

Table 4. Correlations between PMA errors and MMSE in the AD group

\begin{tabular}{ll}
\hline Subtests & Spearman correlations (one-sided) \\
\hline Homonyms - MMSE & $r^{s}=-0.55 ; p=0.004$ \\
Idioms - MMSE & $r^{s}=-0.59 ; p=0.018$ \\
Pronouns - MMSE & $r^{s}=-0.69 ; p=0.002$ \\
\hline
\end{tabular}

The correlation coefficient $r>0.5$ indicates a large effect [36].

\begin{tabular}{lccc}
\hline PMA subtests and & \multicolumn{2}{l}{ Stroop conditions } \\
\cline { 2 - 4 } Spearman correlation & 1 & 2 & 3 (interference) \\
\hline Homonyms & & & \\
$\quad$ Correlation & +0.23 & +0.26 & +0.53 \\
$\quad$ Significance (one-tailed) & 0.11 & 0.08 & 0.001 \\
Idioms & & & \\
$\quad$ Correlation & +0.06 & +0.16 & +0.55 \\
$\quad$ Significance (one-tailed) & 0.37 & 0.19 & 0.001 \\
Pronouns & & & \\
$\quad$ Correlation & +0.18 & +0.29 & +0.60 \\
$\quad$ Significance (one-tailed) & 0.172 & 0.06 & 0.001 \\
\hline
\end{tabular}

The results show a correlation only between the cognitive slowing of executive processes (Stroop 3) and PMA errors.

There seems to be no general relationship between time consumption in Stroop and errors in error scoring tests (PMA errors). But there is a connection between the time consumption in Stroop 3 (regarding executive processes) and the PMA errors. How can we explain this?

\section{Discussion}

The severe deficits in language tests and the positive correlation between PMA errors and the MMSE in the AD group were to be expected [18]. Also expected was the significant slowing of cognitive processing [19-23] and their relationship to the severity of the disease (MMSE). But why is the time consumption increased so much just with executive processes? 
We suspect that the executive subprocesses essentially run in a linear sequence, so that the slowdown of the individual processing steps added up.

How can we explain the positive correlation of PMA errors and Stroop 3 response time (interference condition)? There are 2 complementary explanations: (a) working memory is limited in time, and the strong slowdown of executive subprocesses overwhelmed working memory, and (b) the very strong slowdown of executive subprocesses leads to desynchronization phenomena, to a disintegration of basal and higher cognitive processing steps.

\section{Acknowledgement}

Special thanks to Mrs. Elke Schumann, who was involved in the development of the study design. She has tested a first version of the study design with 9 mild cognitive impairment patients, $15 \mathrm{AD}$ patients and 16 controls [37].

\section{Disclosure Statement}

The authors disclose no relevant financial relationships.

\section{References}

1 Collette F, Van der Linden M, Salmon E: Executive dysfunction in Alzheimer's disease. Cortex 1999;35:57-72.

2 Baddeley AD, Bressi S, Della Sala S, Logie R, Spinnler H: The decline of working memory in Alzheimer's disease: a longitudinal study. Brain 1991;114:2521-2542.

3 Baddeley AD: Exploring the central executive. Q J Exp Psychol A 1996;49A:5-28.

4 Toepper M, Behlo T, Thomas C, Driessen M: Early detection of Alzheimer's disease: a new working memory paradigm. Int J Geriatr Psychiatry 2008;23:272-278.

$>5$ Huntley JD, Howard RJ: Working memory in early Alzheimer's disease: a neuropsychological review. Int J Geriatr Psychiatry 2010;25:121-132.

6 Almor A, Kempler D, MacDonald MC, Andersen ES, Taylor LK: Why do Alzheimer patients have difficulty with pronouns? Working memory, semantics, and reference in comprehension and production in Alzheimer's disease. Brain Lang 1999;67:202-227.

7 Schecker M, Hentrich-Hesse T: Proformen: (Kon-)Textorganisation und Rezeptionssteuerung bei AlzheimerDemenz; in Marillier JF, Dalmas M, Behr I (eds): Text und Sinn. Tübingen, Stauffenburg Verlag, 2005, pp 79-93.

-8 Chenery HJ, Ingram JCL, Murdoch BE: The resolution of lexical ambiguity with reference to context in dementia of the Alzheimer's type. Int J Lang Commun Disord 1998;33:393-412.

-9 Balota DA, Watson JM, Duchek JM, Ferraro FR: Cross-modal semantic and homograph priming in healthy young, healthy old, and in Alzheimer's disease individuals. J Int Neuropsychol Soc 1999;5:626-640.

10 Faupel M, Maisch S, Möller G: Kontextverarbeitung bei dementiellen Syndromen; in Hock C, Hüll M, Schecker M (eds): Die Alzheimer-Krankheit. Tübingen, Narr-Verlag, 2000, pp 67-90.

$\checkmark 11$ Papagno C, Lucchelli F, Muggia S, Rizzo S: Idiom comprehension in Alzheimer's disease: the role of the central executive. Brain 2003;126:2419-2430.

12 Rassiga C, Lucchelli F, Crippa F, Papagno C: Ambiguous idiom comprehension in Alzheimer's disease. J Clin Exp Neuropsychol 2009;31:402-441.

13 Rapp AM, Wild B: Nonliteral language in Alzheimer dementia: a review. J Int Neuropsychol Soc 2011;17:207218.

14 Binetti G, Magni E, Padovani A, Cappa SF, Bianchetti A, Trabucchi M: Executive dysfunction in early Alzheimer's disease. J Neurol Neurosurg Psychiatry 1996;60:91-93.

15 Schecker M: Wortfindung und verbale Flüssigkeit in frühen Stadien der Alzheimer-Krankheit; in Kleiber G, Kochendörfer G, Riegel M, Schecker M (eds): Kognitive Linguistik und Neurowissenschaften. Tübingen, NarrVerlag, 1999, pp 128-150.

16 Bayles KA: Effects of working memory deficits on the communicative functioning of Alzheimer's dementia patients. J Commun Disord 2003;36:209-219.

17 Stockholm J, Vogel A, Grade A, Waldemar G: Heterogeneity in executive impairment in patients with very mild Alzheimer's disease. Dement Geriatr Cogn Disord 2006;22:54-59. 
Schecker et al.: Are There Any Connections between Language Deficits and Cognitive Slowing in Alzheimer's Disease?

18 Schecker M: Pragmatische Sprachstörungen bei Alzheimer-Demenz / Pragmatic Language Disorders in Alzheimer's Disease. Sprache Stimme Gehör 2010;34:63-72.

19 Fisher LM, Freed DM, Corkin S: Stroop Color-Word Test performance in patients with Alzheimer's disease. J Clin Exp Neuropsychol 1990;12:745-758.

20 Nebes RD, Brady CB: Generalized cognitive slowing and severity of dementia in Alzheimer's disease: implications for the interpretation of response-time data. J Clin Exp Neuropsychol 1992;14:317-326.

21 Spieler DH, Balota DA, Faust ME: Stroop performance in healthy younger and older adults and in individuals with dementia of the Alzheimer's type. J Exp Psychol Hum Percept Perform 1996;22:461-479.

22 Bondi MW, Serody AB, Chan AS, Eberson-Shumate SC, Delis DC, Hansen LA, Salmon DP: Cognitive and neuropathologic correlates of Stroop Color-Word Test performance in Alzheimer's disease. Neuropsychology 2002; 16:335-343.

23 Amieva H, Rouch-Leroyer I, Letenneur L, Dartigues JF, Fabrigoule C: Cognitive slowing and learning of target detection skills in pre-demented subjects. Brain Cogn 2004;54:212-214.

24 Saß H, Wittchen U, Zaudig M, Houben I: Diagnostisches und statistisches Manual psychischer Störungen Textrevision - DSM-IV-TR. Hogrefe, Göttingen, 2003.

-25 McKhann G, Drachman D, Folstein M, Katzman R, Price D, Stadlan EM: Clinical diagnosis of Alzheimer's disease: report of the NINCDS-ADRDA Work Group under the auspices of Department of Health and Human Services Task Force on Alzheimer's Disease. Neurology 1984;34:939-944.

-26 Petersen RC, Smith GE, Waring SC, Ivnik RJ, Tangalos EG, Kokmen E: Mild cognitive impairment: clinical characterization and outcome. Arch Neurol 1999;56:303-308.

27 Petersen RC: Mild cognitive impairment: current research and clinical implications. Semin Neurol 2007;27: 22-31.

28 Folstein MF, Folstein SE, McHugh PR: 'Mini-mental state'. A practical method for grading the cognitive state of patients for the clinician. J Psychiatr Res 1975;12:189-198.

29 Yesavage JA, Brink TL, Rose TL, Lum 0, Huang VS, Adey M, Leirer VO: Development and validation of a geriatric depression screening scale: a preliminary report. J Psychiatr Res 1983;17:37-49.

30 Salmaso D, Longoni AM: Problems in the assessment of hand preference. Cortex 1985;21:533-549.

-31 Koss E, Ober BA, Delis DC, Friedland RP: The Stroop color-word test: indicator of dementia severity. Int J Neurosci 1984;24:53-61.

32 'Jeton', Neuropsychological Therapies Petra Rigling: Reha-Service ${ }^{\circledR}$.

-33 Kirshner HS, Webb WG, Kelly MP, Wells CE: Language disturbance. An initial symptom of cortical degenerations and dementia. Arch Neurol 1984;41:491-496.

34 Shuttleworth EC, Huber SJ: The naming disorder of dementia of Alzheimer type. Brain and Language 1988;34: 222-234.

35 Schecker M: Prozesse der Aktivierung des mentalen Lexikons; in Schecker M: Wortfindung und Wortfindungsstörungen. Tübingen, Narr (cognitio 11), 2002, pp 109-132.

36 Sedlmeier P: Jenseits des Signifikanztest-Rituals: Ergänzungen und Alternativen. Meth Psychol Res Online 1996;1:41-63.

37 Schumann E: Gibt es einen Zusammenhang zwischen kognitiver Verlangsamung und Sprachdefiziten bei leichter Alzheimer-Demenz? Eine Pilotstudie; thesis, Universität Freiburg i.Br., 2008. 